\title{
Experimental Study on Fracture Behaviors of Concrete Beams Strengthened with FRP Sheet of Different Width
}

\author{
Juanxia Zhang ${ }^{1,2, *}$, Zhonghui Chen ${ }^{1}$, Xianzhang Guo ${ }^{2}$, Wencheng $\mathrm{Ma}^{2}$ \\ ${ }^{1}$ School of Mechanics and Civil Engineering, China University of Mining and Technology, Beijing, China \\ ${ }^{2}$ College of Resources and Civil Engineering, Northeastern University, Shenyang, China
}

\section{Email address:}

zhang_juanxia@126.com (Juanxia Zhang), chen_zhong_hui@sohu.com (Zhonghui Chen), guoxianzhang@126.com (Xianzhang Guo)

\section{To cite this article:}

Juanxia Zhang, Zhonghui Chen, Xianzhang Guo, Wencheng Ma. Experimental Study on Fracture Behaviors of Concrete Beams Strengthened with FRP Sheet of Different Width. International Journal of Materials Science and Applications. Vol. 5, No. 1, 2016, pp. 31-35.

doi: $10.11648 /$ j.ijmsa.20160501.15

\begin{abstract}
A total of six beams have been tested to investigate the influence of FRP sheet on the mechanical behavior of concrete beam with different FRP sheet width. In addition, the failure mode of the concrete beam and FRP reinforced concrete beams were also studied by numerical simulation method named Realistic Failure Process Analysis (RFPA). The results indicate that, the loading capacity is increased and maximum deflection of the concrete beam is also increased with the increasing of the FRP sheet width. Moreover, the interfacial debonding easily propagates along the interfacial concrete layer at a load that is below the estimated maximum strength of the FRP-strengthened structure. The maximum strength of the FRP sheet in the experiment was not achieved due to the adhesive layer between the concrete and FRP sheet was not strong enough compared with the numerical simulation result. It showed that the FRP sheet width was considered to be an important factor influence the failure mode and load capacity. So does the interface between the concrete and FRP plate.
\end{abstract}

Keywords: Experiments, Concrete Cracks, Failure Mode

\section{Introduction}

The use of Fiber reinforced polymers (FRP) for strengthening reinforced concrete was utilized in construction with their excellent mechanical properties of its strong plasticity, corrosion resistance, tensile and fatigue level [1-3]. This provides an excellent material to take the tensile force to strengthen concrete structures in flexure [4-6]. Many research works have been conducted to investigate the flexural behavior of FRP-reinforced concrete beam [7-8]. Regarding flexural strengthening, some test results had shown that beside the classical failure modes, such as concrete crushing or vertical shear failure, bond failures can occur at the interface between the externally bonded FRP laminate and the concrete element [9]. For the failure mode of the FRP reinforced concrete beams, the interfacial bond failure, occurs before the full strength capacity of the laminate can be developed [10]. Teng studied the end cover separation failure in RC beams strengthened with near-surface mounted FRP strip [11]. A review on the bond behavior of FRP NSM systems in concrete was investigated in [12].

Some researches about the failure process of the FRP reinforced concrete structure had been done by authors [13-14]. Based on the earlier published studies, one of the objectives of this study was to assess the influence of FRP parameters on the performance of concrete beams strengthened with FRP plates. To achieve the objective, an experimental program is implemented where reinforced concrete beam were fabricated, strengthened with FRP laminates, and tested to study the failure mechanisms and the effects of FRP sheet width, moreover, compared with the numerical simulation results. The test data and numerical simulation results would provide valuable information for both research and design applications.

\section{Experiment Study}

\subsection{Layout of Experiment}

The behavior of plain concrete beam and concrete beams strengthened with externally bonded FRP sheet were investigated experimentally. The dimensions and reinforcement details of the two type beams have been shown in Fig. 1 and Fig. 2. Six specimens consist of two plain concrete beams, four FRP strengthened concrete beams with 
same thickness and length but different width of FRP sheet, were tested under three-point bending test by the microcomputer control electron universal testing machines.

The load is applied in the vertical direction with the displacement-controlled loading scheme. For the specimens, w1 indicates the FRP width of FRP reinforced concrete beam, $\mathrm{B} 1$ indicates plain concrete beam, and $\mathrm{W} 1$ and $\mathrm{W} 2$ indicate the FRP sheet width are $25 \mathrm{~mm}$ and $50 \mathrm{~mm}$, respectively. For the FB-W1-1 specimen, it indicates the first specimen $(-1)$ with the FRP width of $25 \mathrm{~mm}$ (W1). So do the other mark number.
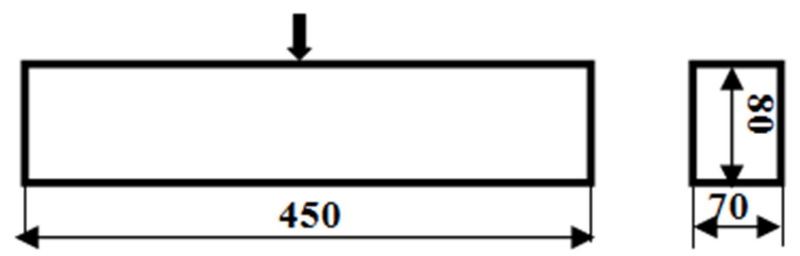

(a) Plain concrete specimen

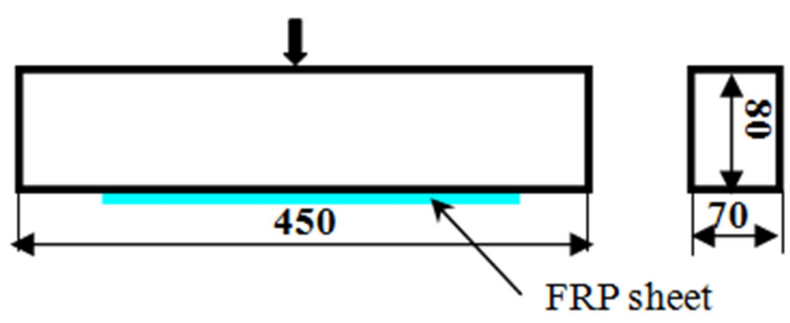

(b) FRP reinforced concrete specimen

Fig. 1. Concrete specimen dimension and loading condition.

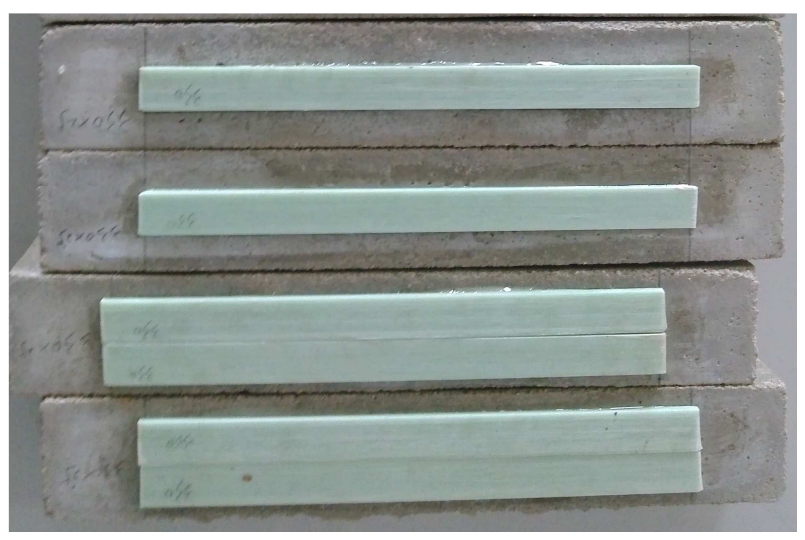

Fig. 2. FRP reinforced concrete specimen.

\subsection{Test Results and Discussion}

Failure Mode of Concrete Specimen. The failure mode was different for the plain concrete beam and FRP reinforced concrete beam, as shown in Fig.3. In the figures, B1-1 indicates plain concrete beam, FB-W1-2 and FW-W2-1 indicate the FRP sheet width is $25 \mathrm{~mm}$ and $50 \mathrm{~mm}$, respectively. All the beams exhibited similar linear behavior from initial loading up to the occurrence of the first microcrack. It can be seen that one dominant flexural crack locally instantaneously occurs at mid span in the bottom of the beam, and progressed rapidly to the direction of loading point with the increasing of load displacement.
For the FB-W1-2 specimen, one dominant flexural crack locally occurs at the bottom of the beam near the midspan of beam and the debonding initiates and propagates from the left edge of the FRP sheet. For the FB-W2-1 specimen, some spalling occurred at beam bottom near the midspan.

In the experiments, the interfacial debonding easily propagate along the interfacial concrete layer due to the induced adhesive shear and peel-off stresses existing in the interface between the FRP plate and concrete, these stresses may cause premature failure at a load that is below the estimated maximum strength of the FRP-strengthened structure. The adhesive shear stress cannot be measured directly through experimental, the related research of adhesive shear stress value was introduced in [15-16].

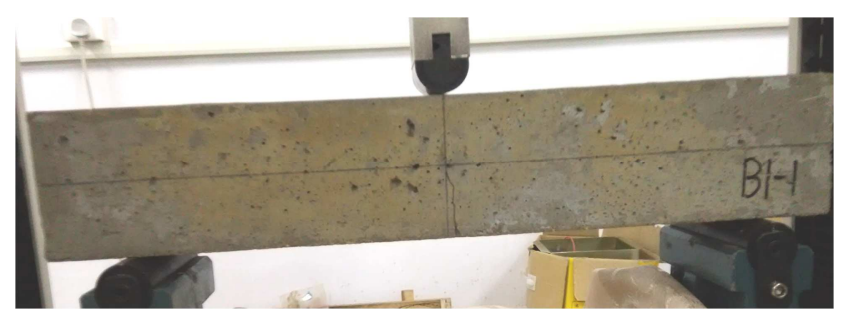

(a) failure pattern of plain concrete beam

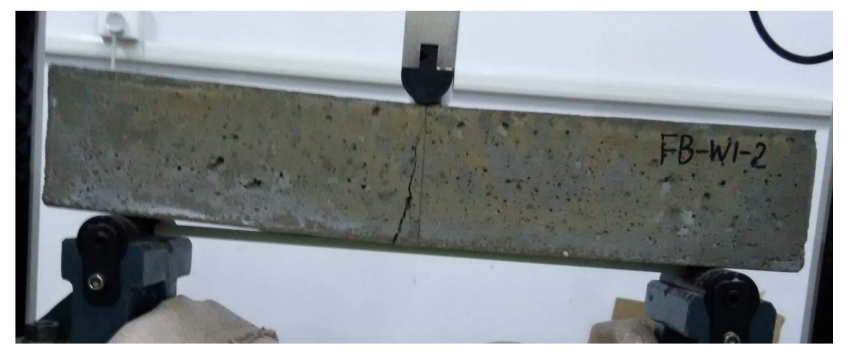

(b) failure pattern of FB-W1 concrete specimen

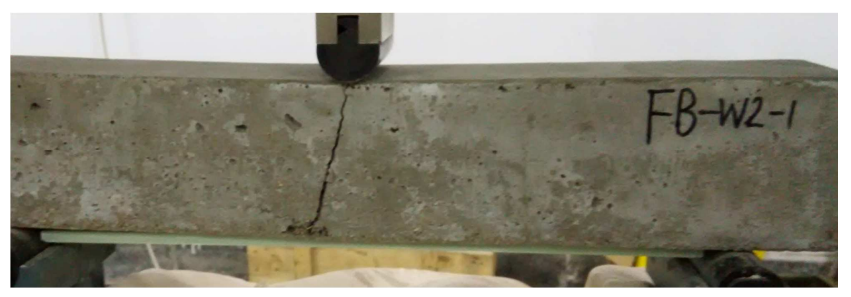

(c) failure pattern of FB-W2concrete specimen

Fig. 3. Failure pattern of the FRP reinforced concrete beam with different FRP sheet width and plain concrete beam.

Load-displacement curves. The structural load-displacement curves obtained by the experiment for the FRP reinforced concrete specimens with different sheet width are compared in Fig. 4. It can be seen that there is no obvious linear behavior from initial loading up to the occurrence of the crack for all the beams, all the beams exhibited nonlinear load-deflection characteristics. But the ultimate load and the ultimate strain of the specimen were increased with the increasing of the FRP sheet width, it due to the different strengthening effects to the beams of the FRP sheet width. Obviously, the maximum tensile strength value was not reached for all the specimens; it due to the adhesive layer 
between the concrete and FRP sheet was not being strong enough and the existing of the adhesive shear and peel-off stresses leading to the premature failure of the beam.

\subsection{Comparison Between Experimental and Numerical Results}

Fig. 5 represents the numerical simulation results conducted by the RFPA3D (Realistic Failure Process Analysis), for the numerical simulation results, no slip allowed at the interface of the bond, namely, there was a perfect bond between the FRP sheet and the concrete. The detailed descriptions about the FRPA have been given in [17]. The load is applied in the vertical direction with the displacement-controlled loading scheme. For the plain concrete beam, only one dominant flexural crack locally occurs at mid span, but for the FRP sheet reinforced concrete beam, more microcracks produced on the concrete adjacent to bond surface, It showed that the numerical simulation result is perfect due to the adhesive layer between the concrete and FRP sheet was strong enough, but a high peel-off stress may cause the FRP sheet and concrete to separate as a unit from the underside of the FRP reinforcement. For the experimental results, the premature debonding mainly occurs due to the weak bonding layer, as shown in Fig. 4.

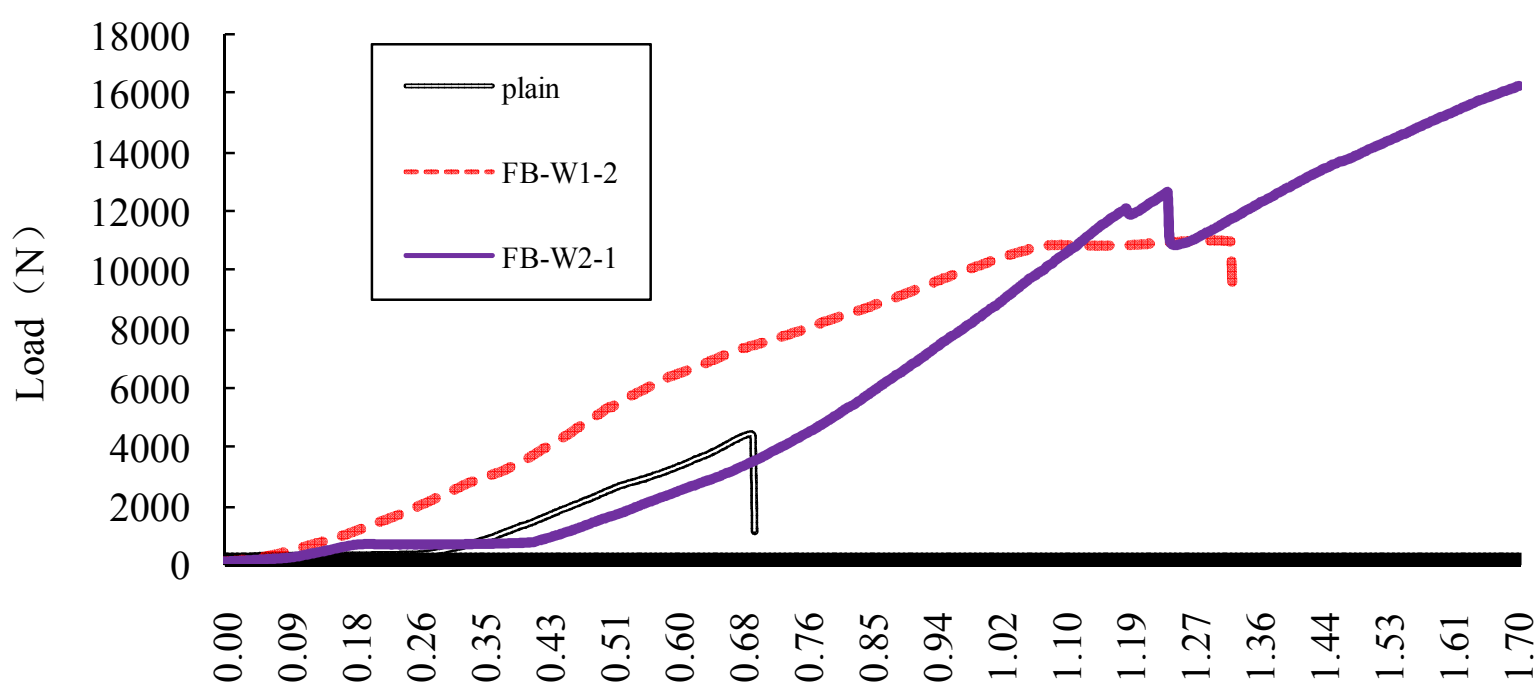

\section{Displacement( $\mathrm{mm})$}

Fig. 4. Load-displacement comparison curves with different FRP sheet length and plain concrete beam.

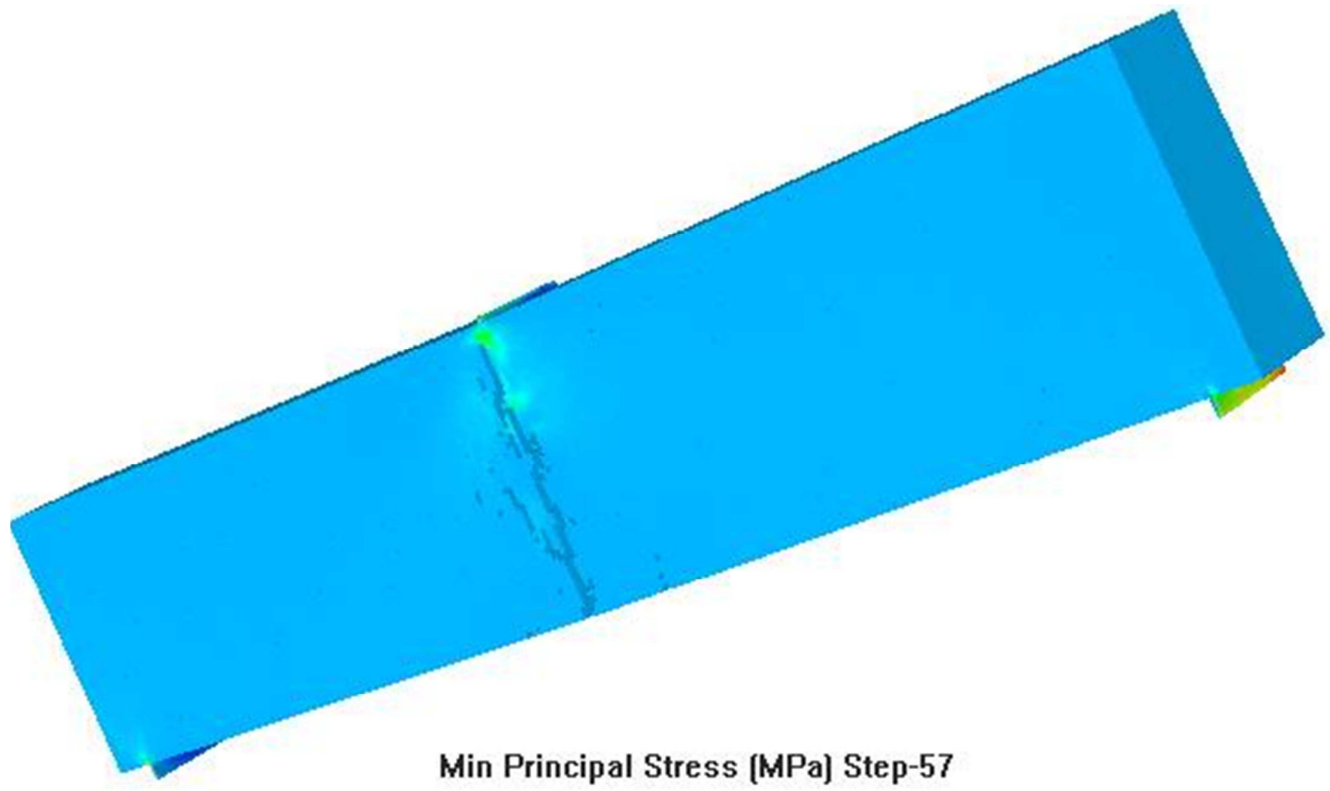

$-2.088 \mathrm{e}+001$ $-1.807 \mathrm{e}+001$

$-1.526 e+001$

$-1.246 e+001$

$-9.646 e+000$

$-6.837 e+000$

$-4.028 \mathrm{e}+000$

$-1.219 e+000$

$1.591 \mathrm{e}+000$

$4.400 \mathrm{e}+000$

(a) plain concrete beam 


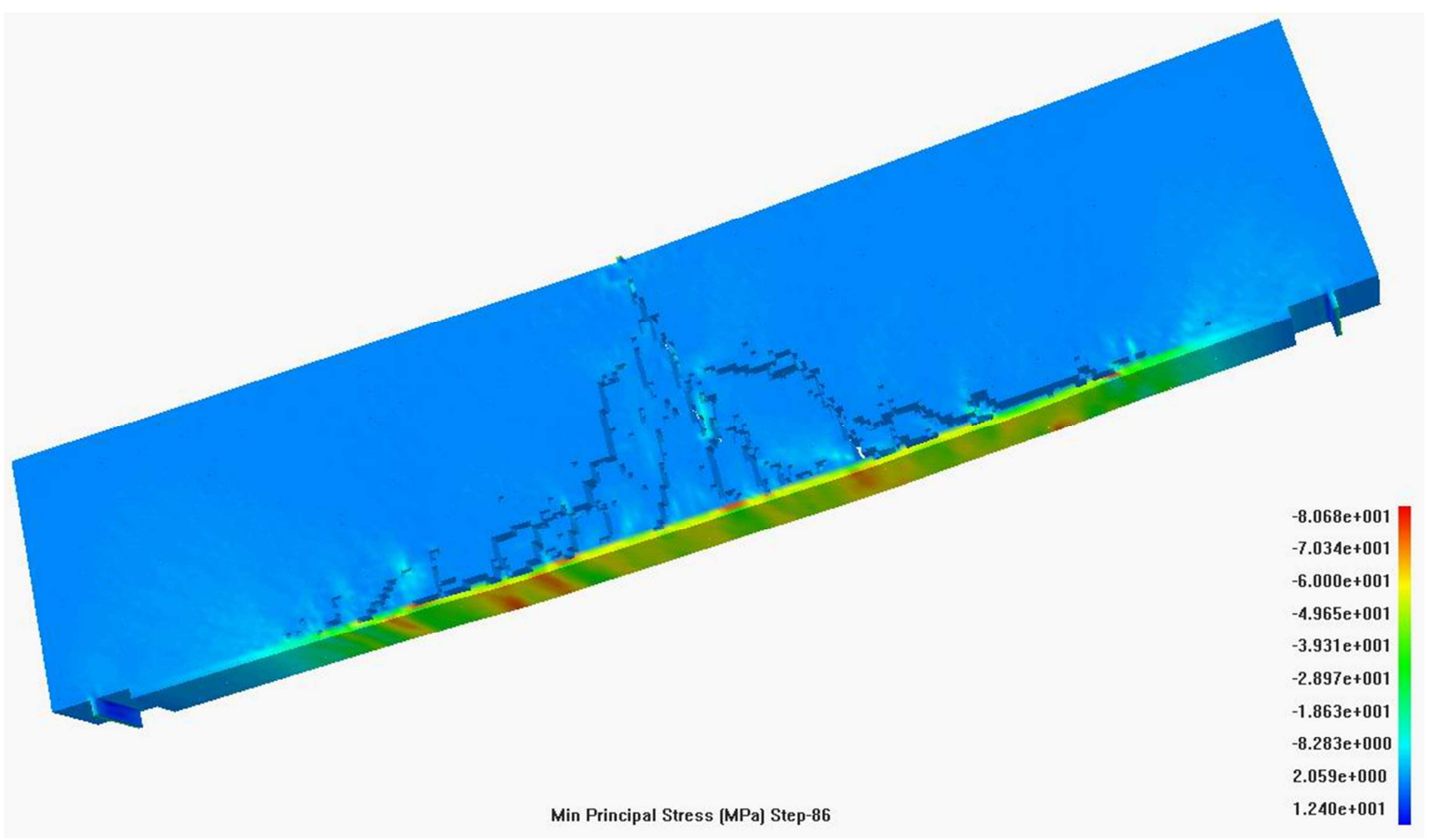

(b) FRP reinforced concrete beam

Fig. 5. The failure mode pictures for the plain concrete beam and FRP reinforced concrete beam simulated by numerical test.2.3. Comparison between Experimental and Numerical Results.

\section{Conclusions}

An investigation into the behavior of plain concrete specimen and FRP-reinforced concrete specimens was presented. A total of six beams were tested to study the influence of FRP-sheet on the failure mode and maximum load under three-point bending test. It can be found that the addition of FRP sheet increases the tensile splitting strength. The FRP sheet can greatly enhance the tensile properties of concrete and improve resistance to cracking. The ultimate load capacity was increased with the increasing of the FRP sheet width. For the numerical simulation results, more microcracks produced on the concrete adjacent to bond surface with the increasing of the FRP sheet length.

From the experiments and numerical simulation results, it can be concluded that the interfacial debonding easily propagate along the interfacial concrete layer due to the induced adhesive shear and peel-off stresses existing in the interface between the FRP plate and concrete. The maximum strength of the FRP sheet in the experiment was not achieved due to the adhesive layer between the concrete and FRP sheet was not strong enough compared with the numerical simulation result. The debonding failure mode mainly occurs in the experiments.

\section{Acknowledgement}

The research is supported by the NSFC (Grant NO.51174208), the National Major Fundamental Research Program (973) (NO.2013CB227903) and the Fundamental Research Funds for the Central Universities (No.
N120423003). The authors are grateful for these supports.

\section{References}

[1] G.B. Maranan, A.C. Manalo, B. Benmokrane, W. Karunasena, P. Mendis. Evaluation of the flexural strength and serviceability of geopolymer concrete beams reinforced with glass-fibre-reinforced polymer (GFRP) bars. Engineering Structures. 2015, 101(15):529-541.

[2] R Z. Al-Zaid, A.Z I. Al-Negheimish, M. A. Al-Saawani, A. K. El-Sayed. Analytical study on RC beams strengthened for flexure with externally bonded FRP reinforcement. Composites: Part B, 2012, 43(2): 129-141.

[3] G.M. Chen, J.G. Teng, J.F. Chen, Q.G. Xiao. Finite element modeling of debonding failures in FRP-strengthened beams: A dynamic approach. Computers and Structures, 2015, 158:167-183.

[4] F. Taheri, K. Shahin, I. Widiarsa. On the parameters influencing the performance of reinforced concrete beams strengthened with FRP plates. Composite structures 2002, 58(2):217-226.

[5] M'hamed Berrezoug Zidani, Khalil Belakhdar, Abdelouahed Tounsi, EI Abbes Adda Bedia. Finite element analysis of initially damaged beams repaired with FRP plates. Composite Structures, 2015, 134:429-439.

[6] Xin Wang, Jianzhe Shi, Gang Wu, Long Yang, Zhishen Wu. Effectiveness of basalt FRP tendons for strengthening of RC beams through the external prestressing technique. Engineering Structures.2015, 101:34-44.

[7] M.S. Mohamed Ali, Deric J. Oehlers, Sung-Moo Park. Comparison between FRP and steel plating of reinforced concrete beams, Composites: Part A, 20013, 2:1319-1328. 
[8] T. Rabczuk, J. Akkermann, J. Eibl. A numerical model for reinforced concrete structures. International Journal of solids and structures.2005, 42(5-6):1327-1354.

[9] M'hamed Berrezoug Zidani, Khalil Belakhdar, Abdelouahed Tounsi, EI Abbes Adda Bedia. Finite element analysis of initially damaged beams repaired with FRP plates. Composite structures, 2015, 134:429-439.

[10] Rui Sun, Enrique Sevillano, Ricardo Perera. Debonding detection of FRP strengthened concrete beams by using impedance measurements and an ensemble PSO adaptive spectral model. Composite Structures. 2015, 25:374-387.

[11] J.G. Teng, S.S Zhang, J.F. Chen. Strength model for end conver separation failure in RC beams strengthened with near-surface mounted (NSM) FRP strips. Engineering Structures, 2016, $110: 222-232$

[12] Mario R.F. Coelho, Jose M. Sena-Cruz, Lus A.C. Neves. A review on the bond behavior of FRP NSM systems in concrete. Construction and Building Materials, 2015, 93:1157-1169.
[13] J. X Zhang, W.C Zhu, C.A Tang, X. Z Guo. Influence of FRP sheet length on failue process of reinforced concrete beam. Journal of Northeastern University (Natural Science). 2011, 32 (10):1495-1498.

[14] J.X Zhang, C.A Tang, W.C Zhu, Z.Z Liang, et al. Numerical simulation of fracturing behaviors of FRP-strengthened concrete members. Engineering mechanics, 2006, 23(12): 143-147.

[15] T. Xu, Z.J He, C.A. Tang, W.C. Zhu, P.G. Ranjith. Finite element analysis of width effect in interface debonding of FRP plate bonded to concrete. Finite elements in analysis and design.2015, 93:30-41.

[16] J.X. Zhang, Numerical investigation on failure mechanism of concrete structures. Doctorthesis, Shenyang, 2006.

[17] C.A Tang, W.C Zhu, Damage and fracture of concrete. Science Press, Beijing, China, 2003. 